\title{
Crystalline Coating and Its Influence on the Water Transport in Concrete
}

\author{
Pavel Reiterman $^{1,2}$ and Jiri Pazderka ${ }^{1}$ \\ ${ }^{1}$ Faculty of Civil Engineering, Czech Technical University in Prague, Thákurova 7, 16629 Prague 6, Czech Republic \\ ${ }^{2}$ University Centre of Energy Efficient Buildings, Czech Technical University in Prague, Třinecká 1024, \\ 27343 Buštěhrad, Czech Republic
}

Correspondence should be addressed to Pavel Reiterman; pavel.reiterman@fsv.cvut.cz

Received 28 November 2015; Revised 26 June 2016; Accepted 11 July 2016

Academic Editor: Gianmarco De Felice

Copyright (C) 2016 P. Reiterman and J. Pazderka. This is an open access article distributed under the Creative Commons Attribution License, which permits unrestricted use, distribution, and reproduction in any medium, provided the original work is properly cited.

The presented paper deals with an experimental study of the efficiency of surface coating treatment based on secondary crystallization as an additional protection of the subsurface concrete structure loaded by moisture or ground water pressure. The aim of the experimental program was the evaluation of the depth impact of the crystalline coating and the assessment of the reliability of construction joints performed on models simulating real conditions of the concrete structure. The evolution of the secondary crystallizing process was monitored using the water absorption test carried out at different depths of the samples. The coefficient of adsorption decreased to $60 \%$ of the reference mixture for a surface layer of up to $40 \mathrm{~mm}$ at 28 days and to $50 \%$ at 180 days after the coating's application. Furthermore, the electrical resistivity method was applied with respect to the nature of measurement and the low accessibility of real subsurface concrete structures. The results of moisture measurement at a depth of 180-190 mm from the surface treated with a crystalline coating showed an essential decrease in moisture content percentage in comparison with untreated specimens (measured 125 days after the coating's application).

\section{Introduction}

Additional protection of buildings against subsurface water and moisture is one of the most frequent types of repairs of buildings. Crystalline coating is a technology which is designed primarily for an additional protection of underground concrete parts of buildings against moisture and subsurface water. The compound for a surface-applied crystalline coat or sprayed layer (in a thickness of $1-1.5 \mathrm{~mm}$ ) is created by mixing crystalline powder material with water. The dry crystalline material (powder), which underlies the crystalline coating, consists of Portland cement, specially treated quartz sand, and a compound of "active chemicals." The chemical composition of active chemicals in the crystalline material is kept confidential by all producers. The crystalline material's waterproofing effect in concrete is achieved by the reaction of various chemical components contained in the solution when combined within the concrete matrix [1]. The process only works when the porous system of concrete reaches a sufficient level of moisture and has open character, which is typical for the concrete of lower grades. Sufficient transport properties of the concrete are probably the necessary prerequisite for the crystalline agent efficiency. Therefore, perfect moistening of the coated surface is very important. In the case of a shortage of moisture inside the concrete structure, the crystalline coating's components lie dormant.

Crystalline materials in principle work so that the chemical components chemically react with a cementitious matrix in the process of hydration with the temporary formation of $\mathrm{Ca}(\mathrm{OH})_{2}$ and the subsequent formation of disilicate and polysilicate anions. It is probable that the cumulative process is accompanied by the formation of $3 \mathrm{Ca} \cdot 2 \mathrm{SiO}_{2} \cdot 3 \mathrm{H}_{2} \mathrm{O}$, together with the creation of $3 \mathrm{CaO} \cdot \mathrm{Al}_{2} \mathrm{O}_{3} \cdot \mathrm{Ca}(\mathrm{OH})_{2} \cdot 12 \mathrm{H}_{2} \mathrm{O}$ [2]. The product of this chemical reaction is a growth of needle-shaped crystals inside the pore structure of concrete. The needle-shaped crystals change the pore structure of concrete, which results in its waterproofing effect. Thanks to this, concrete with a crystalline coating is effective against 

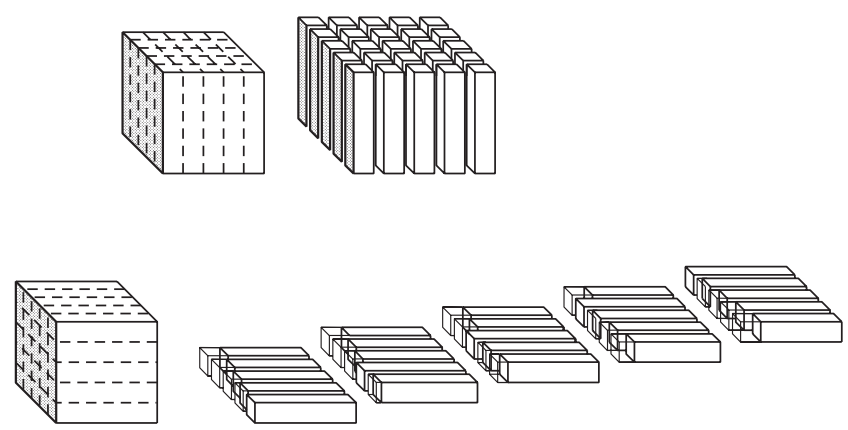

(a)

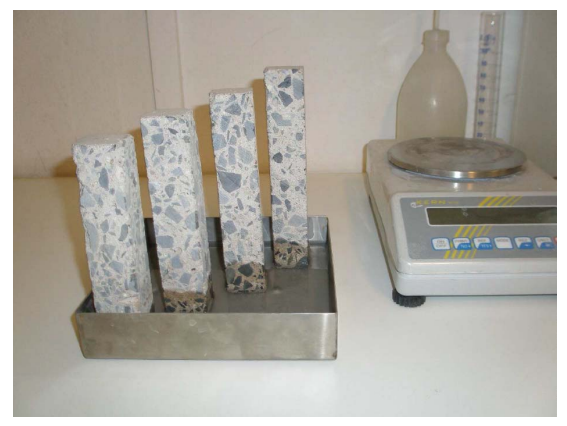

(b)

FIGURE 1: (a) Documentation of the preparation of prismatic specimens (scheme). (b) Documentation of the preparation of prismatic specimens (measurement).

hydrostatic pressure as demonstrated by many successful applications [3-7]. There have also been many experimental laboratory measurements of the waterproofing ability of crystalline waterproofing systems in the past, focused on verifying the waterproofing [8-13] and the durability [1417] of concrete with crystalline coatings or admixtures. An integral crystalline waterproofing admixture works on a principle similar to crystalline coatings (both are based on the same crystalline material), but the admixture is designed for newly constructed buildings.

The results of the above-mentioned tests are very convincing; thus, it is possible to declare the water impermeability and high durability of concrete with the crystalline coating. The waterproofing effect of the crystalline coat is conditioned on a strict technological discipline, especially the thorough curing of the fresh coat [18]. As mentioned above, without a sufficient level of moisture inside the pore structure during at least two or three days after the coat application, the waterproofing effect is missing. Generally, the importance of the curing of fresh concrete is well known; it is also confirmed by the results presented in literature [19]. A significant danger to the overall waterproofing effect of the crystalline coating (and also the admixture) is the cracking of concrete (problems of cracks in concrete were analyzed in literature $[5,20])$. It is necessary to note that the experimental works were performed on the mortars or concrete mixtures of low mechanical properties and presumed higher hydraulic conductivity, respectively. Construction joints in concrete may also have a negative effect here (the problems with joints are described in literature [21]).

In addition to the aforementioned properties of crystalline materials, there are many other research works focused on the crystalline technology which include, for example, the appropriateness of using steel fibers in concrete with crystalline admixtures [22], the problems with fly-ash usage in crystalline materials [23], the uniform design for the preparation of crystalline waterproofing coatings [24], changes in the water vapor permeability of concrete due to crystalline materials [25], or the comparison of the physical properties of both crystalline technologies (coating and admixtures) and the analyses of the financial aspect of their use [26].

\section{Experimental Program}

The performed experimental program was focused on the evaluation of the reliability of crystalline coating as an additional solution for reducing water transport into concrete. A couple of measurement methodologies were carried out to quantify the crystalline effect of the introduced surface treatment. With respect to the nature of the studied issue, the combination of direct and indirect measurement methodologies was chosen. For the direct evaluation of decreasing the water transport in concrete, the water absorption test whose suitable resolution in the application on mortars had been proved in previous research was selected [27]. The second one is presented by electric resistivity methods, which are often used for in situ measurements.

2.1. Depth Effect of Crystalline Coating Measured through the Water Absorption Test. The assessment of the depth impact of crystalline coating was studied on prismatic specimens with dimensions of approximately $40 \times 40 \times 200 \mathrm{~mm}^{3}$, which were cut out of original cubes with an edge of $200 \mathrm{~mm}$. The coating was applied on one lateral side of concrete cubes at the age of one month, and the specimens were then kept in ambient laboratory conditions. In selected time intervals after the coating's application (28, 60, 120, and 180 days), sets of cubes were freed from the coating and sliced up into prisms which were subjected to the water absorption test. The prisms were sliced up with different orientations, parallel and perpendicular to the applied coating. The prisms sliced up parallel to the coating then introduced four sections diversely influenced by secondary crystallization.

The lower base of the prisms of the perpendicular orientation was constituted by a treated surface, so the effect of the studied coating changed with the height of prisms. That is why the lower parts of these prisms were gradually cut off (each $10 \mathrm{~mm}$ ) to obtain a better resolution. The preparation of prisms is documented in Figure 1(a) (scheme) and Figure 1(b) (measurement).

Absorption was measured by using prismatic specimens which were partially wetted (just up to $5 \mathrm{~mm}$ ) in a water basin. In selected time intervals, the growth of the water 


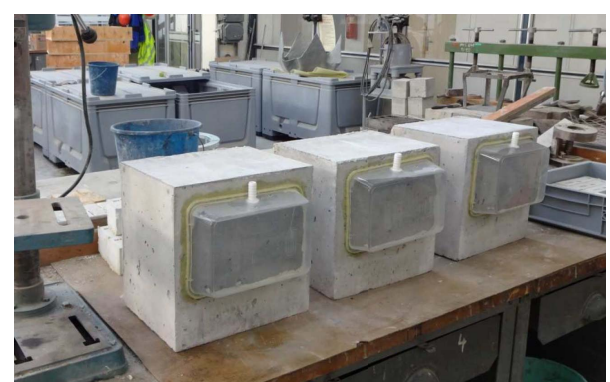

FIGURE 2: Set of specimens with the moisture load arrangement.

mass absorbed into hardened concrete was gravimetrically recorded. The absorption coefficient $A\left(\mathrm{~kg} \cdot \mathrm{m}^{-2} \mathrm{~s}^{-1 / 2}\right)$ was calculated for the time of ten minutes for each set of prisms according to (1), where $i$ is the cumulative mass ingress of water $\left(\mathrm{kg} \cdot \mathrm{m}^{-2}\right)$ and $t$ time (s). The above-described test presents a very quick way of the water capability assessment:

$$
i=A \cdot t^{1 / 2} .
$$

The above-described laboratory procedure was carried out in three different time periods to monitor the evolution and the velocity of the crystallizing process. The first measurement was performed before the coating's application at the concrete's age of 28 days and continued after 28, 60, 120, and 180 days. The selected time period of 10 minutes for the water absorption test documents the evolution of progressive crystallization of the studied surface treatment.

\subsection{Depth Effect of Crystalline Coating Measured by the Elec-} trical Resistivity Method. There are two physical methods of determining the crystalline coating depth effect: chemical analysis and radar scanning of damp concrete. The chemical analysis can detect changes in the chemical composition inside the material at different depths, but this method is not able to observe the changes in the physical properties of the material. The radar scanning of damp concrete uses the following principle: according to the amount of water in radar images it is possible to determine the distance between the outside surface and the water-resistant microstructure. Subtracting this distance from the interior surface of the structure, it is possible to determine the depth of the crystalline coat's waterproofing effect. The authors of this paper have tried an alternative method using electrical resistivity.

The objective of the experimental program was to verify the coating's ability to create an impermeable layer at a specific depth (to reduce the transport of liquid water into the concrete structure). The test parameters were adjusted with respect to the existing concrete structure (basement wall of a block of flats in Prague) to accurately simulate real conditions. The measurement was carried out in the laboratories of the Faculty of Civil Engineering's Experimental Centre, CTU, in Prague.

Rectangular samples $(300 \times 300 \times 220 \mathrm{~mm})$ were designed and produced, where the last dimension was similar to the thickness of the studied basement wall. Altogether, three sets of blocks were produced; each set was composed of three samples. The specimens were made of concrete C20/25 according to BS EN 12390-2 [28]. After 28 days of curing, a crystalline coating (Xypex Concentrate) was applied on the front surface $(300 \times 300 \mathrm{~mm})$ of one set of specimens. The application was performed according to the technical sheet of the producer (Xypex), which includes the surface treatment, application, and subsequent curing. The other two sets of specimens were not coated.

Two sets of specimens (one treated and one nontreated with a crystalline coating) were then equipped with an additional apparatus to simulate the moisture conditions (Figure 2). The simulation apparatus consisted of a plastic reservoir glued to the vertical wall of the specimen with an opening so that the fluid could be refilled. The waterproof performance of this joint was essential for the designed simulation and the interpretation of the measured data. In the case of specimens treated with a crystalline coating, the apparatus was fastened on the opposite (nontreated) surface of the specimen. The reservoirs of all specimens were then filled with water. The level of the water in the reservoirs was kept constant to ensure that the initial moisture gradient was maintained. The specimens of the last set were placed under normal laboratory conditions, without any direct moisture loading.

A couple of $6 \mathrm{~mm}$ diameter holes, $90 \mathrm{~mm}$ apart, were drilled into each specimen. These were used for the placing of brush sensors of the electrical resistivity moisture meter, to measure the gravimetric moisture content in the samples. The measurement was performed at a distance of $30-40 \mathrm{~mm}$ from the loaded surface. The Greisinger GMH 3810 electrical resistivity moisture meter with implemented material characteristics was selected for the testing. The determination of moisture content is based on the measurement of the electrical conductivity of a porous material (concrete in this case). The applied apparatus measures the value of specific electrical resistivity, which is fundamentally influenced by the actual moisture content. A previous calibration or implementation of material characteristics is necessary for the final determination of the gravimetric moisture content. The scheme and organization of testing are shown in Figures 3 and 4.

The measurement with the electrical resistivity moisture meter was performed on all sets of specimens at different time intervals: 28, 45, 90, 125, and 132 days after the production of the specimens. The experimental program was completed by the destruction of each specimen. This was carried out at right angles to the moisture load direction using a hydraulic press. The fragments were then immediately subjected to direct gravimetric measurement of their moisture content for the verification of the data provided by the electrical resistivity moisture meter. The fragments were removed from the area where the moisture measurement using brush sensors had been performed (about $30-40 \mathrm{~mm}$ from the loaded surface). The drying of fragments was carried out in standard conditions of $105^{\circ} \mathrm{C}$ to constant weight. The moisture determination demonstrated variations of up to $5 \%$ in both types of measurements. 


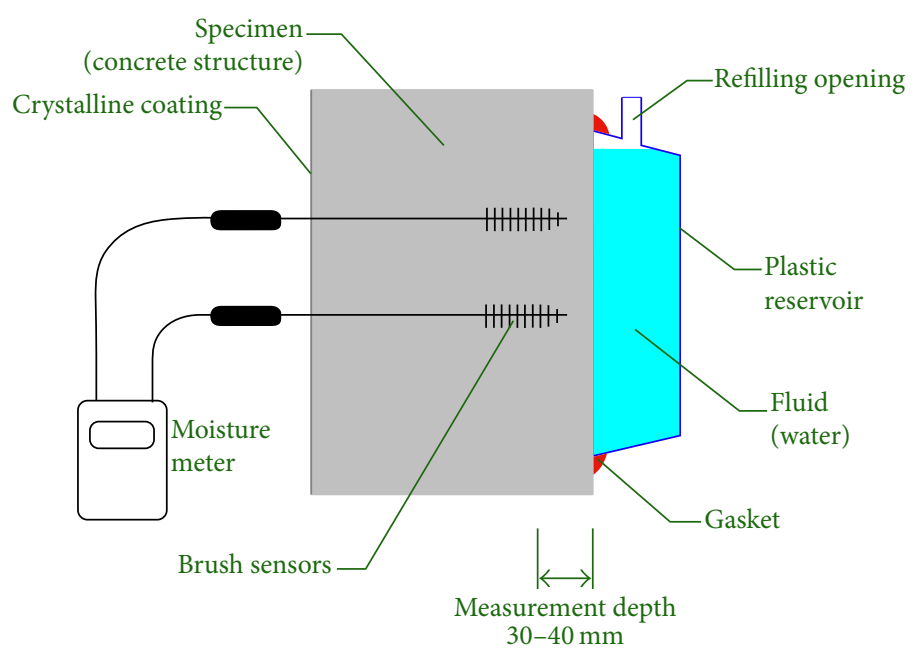

FIGURE 3: Scheme of the test arrangement.

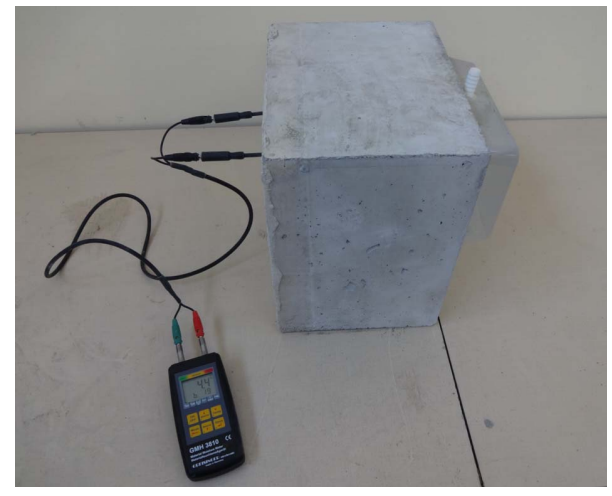

FIGURE 4: Real measurement by the electrical resistivity moisture meter.

2.3. Crystalline Coating Reliability Affected by the Construction Joints in Concrete. To simulate a real situation, a set of realsized specimens of reinforced concrete C20/25 which represented water reservoirs was designed. To create construction joints, the specimens' preparation was divided into three stages so horizontal and vertical construction joints could be created. A couple of PVC tubes were inserted into the moulds of the walls to model the holes for folding elements of system's formwork. The production of concrete specimens is illustrated in Figures 5(a) and 5(b). One concrete model was treated with crystalline coating at the age of one month; the other one served as a reference one. Then, the concrete specimens were prepared for the electric resistivity measurement as described above and the PVC tubes were choked up. The organizing of the experiment presents the state of the building with finished setting, for example, the state before reconstruction, where the equilibrium depth of the cracks is expected.

The following measurement was provided by using the electrical resistivity method in areas of construction joints running periodically during the next 180 days. Thanks to the depth impact of the crystalline coating, a gradual decreasing of moisture in concrete was expected. Attention was paid to specific areas of construction joints and folding tubes; the monitored areas are drawn in Figure 5(a) (scheme) and Figure 5(b) (model).

\section{Results and Discussion}

3.1. Depth Effect of Crystalline Coating Measured through Water Absorption. The measurement of the coefficient of water absorption was performed in various time periods. The results of both types of reference specimens for selected time intervals are shown in Figures 6 and 7. The time period assigned " 0 " represents the age of 28 days when parts of cubes were treated with the crystalline coating. The values of the absorption coefficient of the specimens sliced up parallel to the coating present the profile of transport properties of the original cube for each time period. Peripheral prisms (0-40 $\mathrm{mm}$ and $160-200 \mathrm{~mm})$ exhibited increased values of the absorption coefficient because of the absence of coarse aggregates in the concrete cover. The results determined for all time periods are very similar.

Changing the water transport properties of the concrete cover is shown in Figure 7. The values of the coefficient of absorption measured at different depths are similar for each time period, too.

The application of the crystalline coating led to the gradual reduction of water transport properties of the used concrete. Figure 8 documents the evolution of secondary crystallization considered by the decreasing values of the absorption coefficient across the cubic specimen. The first measured section presenting $0-40 \mathrm{~mm}$ of the original cube was the most affected area. After 180 days, the absorption coefficient was reduced to less than $50 \%$ of the reference measurement. The second depth profile $(40-80 \mathrm{~mm})$ after 180 days was not influenced by the crystallization so much and the reduction was by about $20 \%$. The remaining sections were affected by the crystallizing coating very slightly and the absorption coefficient of the last one was on the reference measurement level. 

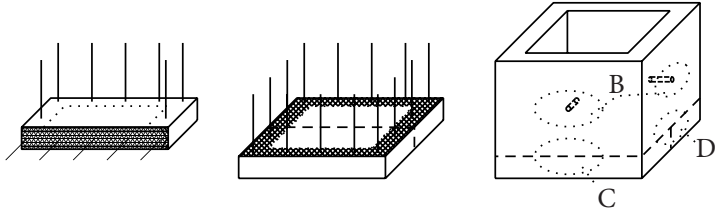

(a)

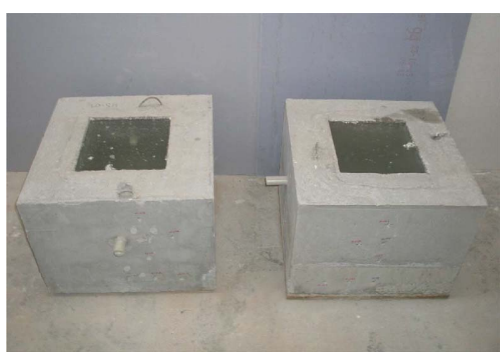

(b)

FIGURE 5: (a) Illustration of concrete reservoirs production (scheme). (b) Documentation of the models.

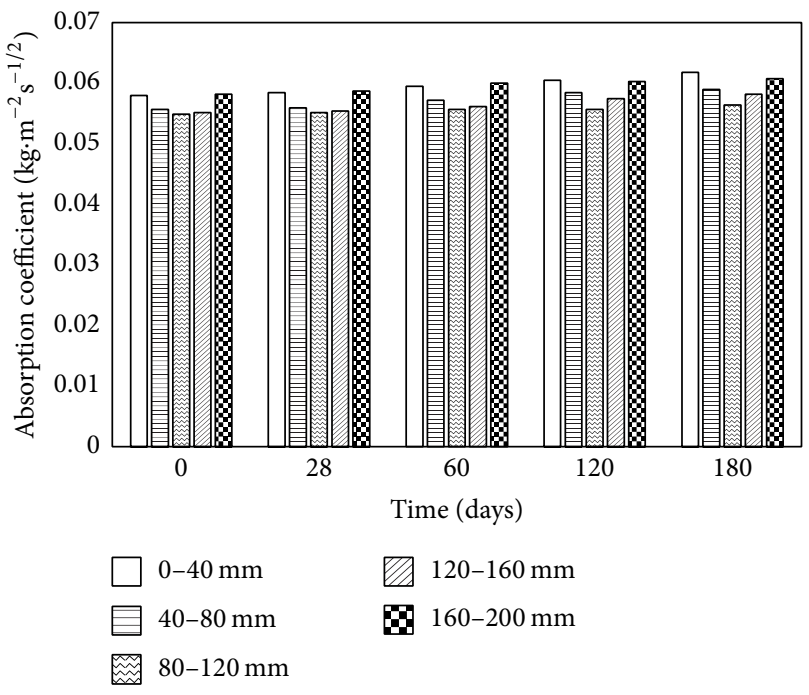

FIGURE 6: Evolution of the absorption coefficient of reference specimens: parallel with the coating.

The progress of secondary crystallization is well noticeable for the measurement carried out on the concrete cover $(0-40 \mathrm{~mm})$ by using specimens sliced up perpendicularly to the coating. Detailed results of the absorption coefficient are shown in Figure 9. This setting of the measurement allowed a better resolution of the depth impact of the crystalline coating on the surface layer. The sealing effect of the applied coating is obvious after 28 days for the section of $0-20 \mathrm{~mm}$ of the concrete surface when the absorption coefficient values reached the level of $50 \%$ of the reference measurement. The crystalline effect is inwardly progressively decreasing. The original water transport properties of the concrete cover presented by $20 \mathrm{~mm}$ were reduced to $30 \%$ due to the crystalline coating.

\subsection{Depth Effect of Crystalline Coating Measured by the Elec-} trical Resistivity Method. The results of moisture measurement under the loaded surface at a depth of $30-40 \mathrm{~mm}$ (180-190 $\mathrm{mm}$ from the surface treated with the crystalline coating) are shown in Table 1 . An essential decrease in the moisture content percentage by weight is evident, in the case of specimens treated with the crystalline coating, over time.

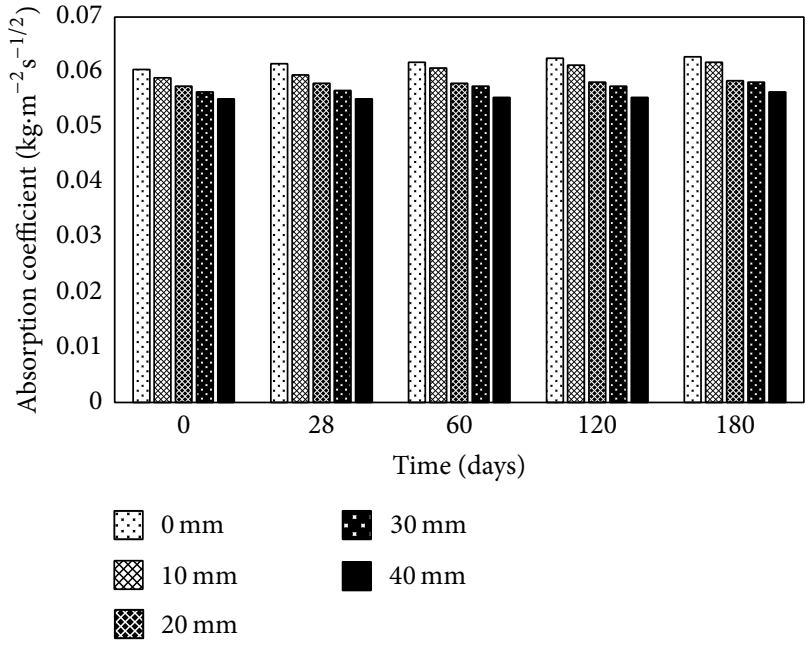

Figure 7: Evolution of the absorption coefficient of reference specimens: perpendicular to the coating.

After 125 days, the moisture content level is equal to the reference set of samples cured under common laboratory conditions, which were not loaded by moisture. The gradual reduction of the moisture content of treated specimens over time is shown in Figure 10.

\subsection{Crystalline Coating Reliability Affected by the Construction} Joints in Concrete. When concrete models were filled with water, leakage of all joints was observed on the wet concrete surface; escaped water was continuously refilled. The evolution of moisture content in the monitored areas of concrete reservoirs is documented in Figures 11 and 12. The initial periods of measurement were affected by the high level of moisture given by the rest of mixing water. The results of measurement for the reference model (Figure 11) constitute progress to the equilibrium moisture state for given conditions. It is noticeable that the final moisture is increased in the critical sections.

The decrease in the moisture content of the concrete reservoir with the outside application of the crystalline coating is shown in Figure 12. The gradual reduction of the moisture content determined using the electrical resistivity method is the case of the treated model affected by the natural 
TABLE 1: Evolution of moisture content in time.

\begin{tabular}{|c|c|c|c|c|c|c|c|c|c|c|c|c|}
\hline \multirow{2}{*}{ Type of specimen } & \multirow{2}{*}{ Exposure } & \multirow{2}{*}{ Number } & \multicolumn{10}{|c|}{ Weight moisture of concrete (\%) } \\
\hline & & & \multicolumn{2}{|c|}{28 days } & \multicolumn{2}{|c|}{45 days } & \multicolumn{2}{|c|}{90 days } & \multicolumn{2}{|c|}{125 days } & \multicolumn{2}{|c|}{132 days } \\
\hline \multirow{3}{*}{ C20/25 without coating } & \multirow{3}{*}{ Wet } & 1 & 8.9 & \multirow{3}{*}{8.9} & 7.8 & \multirow{3}{*}{8.4} & 9.1 & \multirow{3}{*}{8.8} & 7.5 & \multirow{3}{*}{7.8} & 7.8 & \multirow{3}{*}{7.9} \\
\hline & & 2 & 8.9 & & 8.7 & & 8.5 & & 7.7 & & 8.3 & \\
\hline & & 3 & 9.0 & & 8.8 & & 8.9 & & 8.1 & & 7.5 & \\
\hline \multirow{3}{*}{ C20/25 with coating } & \multirow{3}{*}{ Wet } & 1 & 8.8 & \multirow{3}{*}{8.5} & 8.0 & \multirow{3}{*}{7.8} & 6.6 & \multirow{3}{*}{6.1} & 4.1 & \multirow{3}{*}{4.7} & 4.3 & \\
\hline & & 2 & 8.7 & & 7.8 & & 5.9 & & 4.1 & & 4.5 & 4.6 \\
\hline & & 3 & 8.1 & & 7.7 & & 5.8 & & 5.9 & & 5.1 & \\
\hline \multirow{3}{*}{ C20/25 without coating } & \multirow{3}{*}{ Dry } & 1 & 5.1 & \multirow{3}{*}{5.7} & 4.8 & \multirow{3}{*}{5.3} & 4.7 & \multirow{3}{*}{4.9} & 3.8 & \multirow{3}{*}{4.6} & 3.6 & \\
\hline & & 2 & 6.1 & & 5.9 & & 5.1 & & 5.2 & & 5.2 & 4.4 \\
\hline & & 3 & 5.9 & & 5.1 & & 4.8 & & 4.8 & & 4.4 & \\
\hline
\end{tabular}
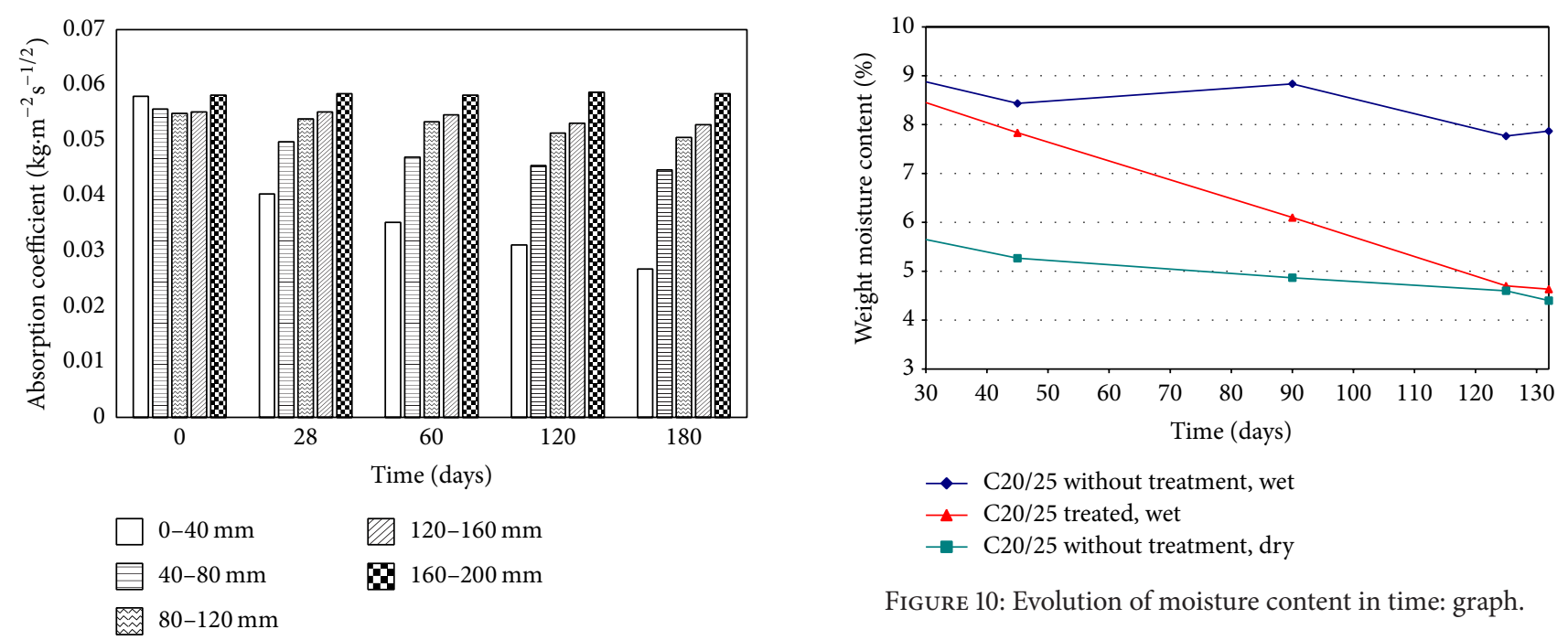

FIGURE 10: Evolution of moisture content in time: graph.

FIGURE 8: Evolution of the absorption coefficient of treated specimens: parallel with the coating.

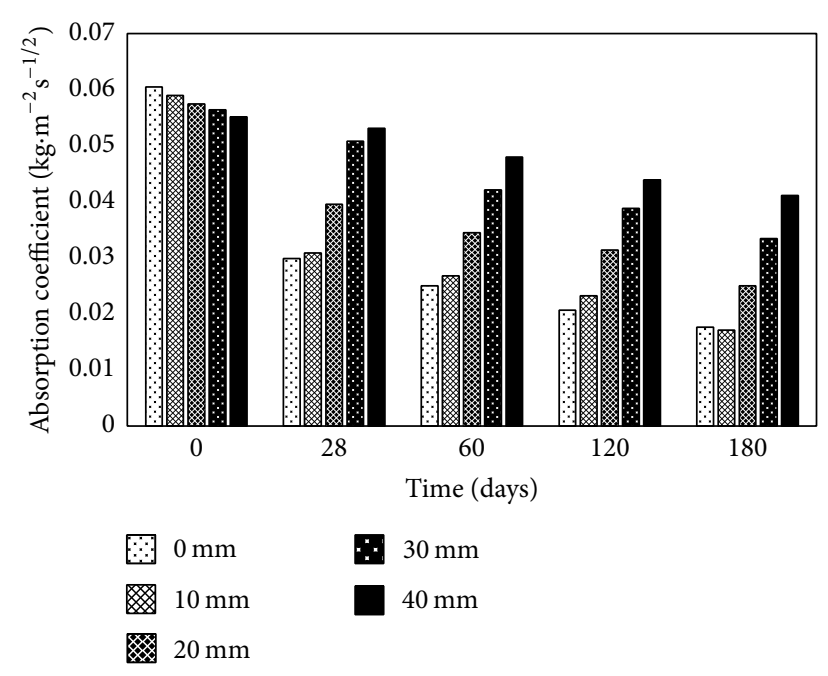

FIGURE 9: Evolution of the absorption coefficient of treated specimens: perpendicular to the coating.

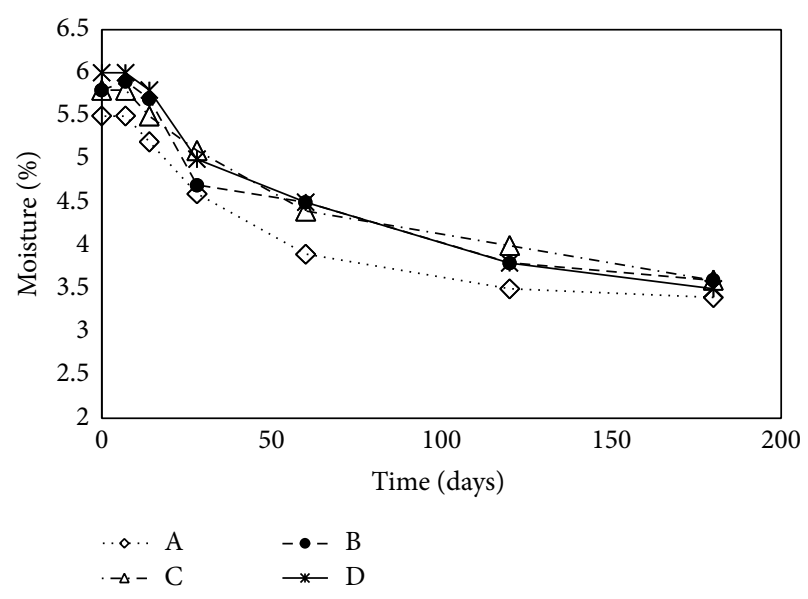

FIGURE 11: Evolution of moisture content of the reference model.

loss of the rest of mixing water. On the other hand, the comparison with the reference model provided the proof of the crystalline coating's efficiency. The final moisture content values are lower by about $1.0 \%$ absolutely. 


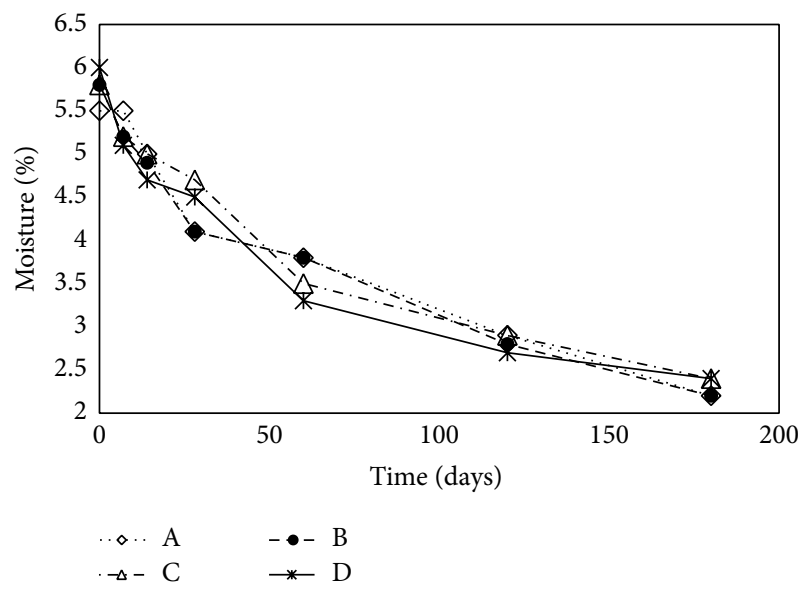

FIGURE 12: Evolution of moisture content of the reference model.

\section{Conclusions}

The depth impact of crystalline coating and its evolution in time was studied in the performed experimental program. The motivation was to assess the sealing effect of the present modern solution applicable as an additional protection of subsurface concrete structures. The results of the tests presented in the paper have confirmed that the crystalline coating (Xypex) is able to change the concrete structure at a specified depth under the cured surface. This process resulted in the creation of the waterproof concrete structure.

There was confirmed the ability of the crystalline coating to reduce water ingress in the area of the construction joints in the experimental program; however, the test organizing presents the state of the structure with the finished setting. Brittle character of the secondary hydration products prevents the efficient sealing effect of the active cracks. The range and the speed of secondary hydration caused by the crystalline coating are dependent on (inter alia) the amount of water inside the concrete: a higher degree of saturation means a higher efficiency. This is apparent from the comparison of the results between the water absorption test and the test using the electrical resistivity method. In the case of the measurement using the electrical resistivity method, the test specimens were loaded by water pressure, which resulted in a large amount of water in the concrete structure. Thanks to this, the secondary hydration (waterproof structure creation) was executed in a larger scale and more rapidly. Nevertheless, the secondary hydration of crystalline materials is very slow process even in the ideal conditions: the impact was evident after several months. In contrast to this, drier specimens used in the water absorption test did not support the secondary hydration so much as in the previous case and resulted in a slower creation of the waterproof structure. It can be concluded that the water doping is one of the crucial prerequisites for the efficiency of the studied coating. The efficiency of the crystalline coating is probably determined by the character of porous system of the concrete. It can be expected that, in case of concretes with increased density and close porous system, the efficiency would be considerably reduced. However, such focused experimental works using high performance concrete (HPC) have not been published yet.

\section{Competing Interests}

The authors declare that there are no competing interests.

\section{Acknowledgments}

The paper was created with support from the Research Project no. TA03010501 funded by the Technology Agency of the Czech Republic and the OP RDI Project no. CZ.1.05/2.1.00/03.0091 funded by the European Union, which collectively supported presented research.

\section{References}

[1] V. Rahhal, V. Bonavetti, A. Delgado, C. Pedrajas, and R. Talero, "Scheme of the Portland cement hydration with crystalline mineral admixtures and other aspects," Silicates Industriels, vol. 74, no. 11-12, pp. 347-352, 2009.

[2] C. Edvardsen, "Water penetrability and autogenous healing of separation cracks in concrete," Betonwerk und Fertigteil-Technik, vol. 62, no. 11, pp. 77-85, 1996.

[3] N. Bowling, "Concrete admixture stabilizes tallest building in European Union,” Building Design \& Construction, 2012.

[4] L. Connell, "Crack repair system stops water in its tracks," Concrete International, vol. 29, no. 5, pp. 50-52, 2007.

[5] V. T. N. Dao, P. F. Dux, P. H. Morris, and A. H. Carse, "Performance of permeability-reducing admixtures in marine concrete structures," ACI Materials Journal, vol. 107, no. 3, pp. 291296, 2010.

[6] F. Klouda, "Concrete crystallisation gives India's greenest airport wings," Concrete, vol. 44, no. 3, pp. 33-34, 2010.

[7] F. Klouda, "The Capri South Beach fully protected with crystalline waterproofing-admixture-treated concrete," Concrete Engineering International, vol. 12, no. 4, pp. 59-60, 2008.

[8] H.-J. Ji, Y. Yang, S.-G. Zhou, and Y. Yuan, “Tentative study of a new cement waterproof paint," Journal of Xian University of Architecture and Technology, vol. 40, no. 1, pp. 80-86, 2008.

[9] R. L. Munn, G. Kao, and Z. T. Chang, "Performance and compatibility of permeability reducing and other chemical admixtures in Australian concretes," in Proceedings of the 7th CANMET/ACI International Conference on Superplasticizers and Other Chemical Admixtures in Concrete, pp. 361-379, Berlin, Germany, 2003.

[10] X. Shaozhu, "Research and development of cement-based permable crystallization type waterproof materials abroad," China Building Waterproofing, vol. 6, 2001.

[11] K. Wang, T. Hu, and S. Xu, "Influence of permeated crystalline waterproof materials on impermeability of concrete," Advanced Materials Research, vol. 446-449, pp. 954-960, 2012.

[12] G.-M. Wang and J.-Y. Yu, "Effect of catalytic crystalline waterproofing coating on performance and microstructure of concrete," Journal of Wuhan University of Technology, vol. 28, no. 3, pp. 29-31, 2006.

[13] Y. Zhang, X. Du, Y. Li, F. Yang, and Z. Li, "Research on cementitious capillary crystalline waterproofing coating for underground concrete works," Advanced Materials Research, vol. 450451, pp. 286-290, 2012. 
[14] S. Bohus and R. Drochytka, "Cement based material with crystal-growth ability under long term aggressive medium impact," Applied Mechanics and Materials, vol. 166-169, pp. 1773-1778, 2012.

[15] L. Gao, L. Kong, and C. Hui, "Effect of catalytic crystalline waterproof coatings on steel reinforcement corrosion of concrete," Advanced Materials Research, vol. 79-82, pp. 1083-1086, 2009.

[16] J. Wu, G. Lu, L. Lu, Z. Ya, and J. Yu, "Influence of Shenkebao permeable crystalline admixture on concrete resistance to chemical corrosion and freeze-thaw cycles," Jiangsu Building Materials, no. 2, pp. 18-21, 2010.

[17] T. Scancella and J. Robert, "Use of Xypex admixture to concrete as an inhibitor to reinforcement steel corrosion," in Proceedings of the Materials Engineering Conference, vol. 2, pp. 1276-1280, 1996.

[18] T.-L. Weng and A. Cheng, "Influence of curing environment on concrete with crystalline admixture," Monatshefte fur Chemie, vol. 145, no. 1, pp. 195-200, 2014.

[19] A. Cwirzen, R. Engblom, J. Punkki, and K. HabermehlCwirzen, "Effects of curing: comparison of optimised alkaliactivated PC-FA-BFS and PC concretes," Magazine of Concrete Research, vol. 66, no. 6, pp. 315-323, 2014.

[20] G. Bertagnoli, G. Mancini, and F. Tondolo, "Early age cracking of massive concrete piers," Magazine of Concrete Research, vol. 63, no. 10, pp. 723-736, 2011.

[21] K.-H. Yang, J.-I. Sim, J.-H. Kang, and A. F. Ashour, "Shear capacity of monolithic concrete joints without transverse reinforcement," Magazine of Concrete Research, vol. 64, no. 9, pp. 767-779, 2012.

[22] M. R. Zhou, G. J. Cui, L. J. Gao, and H. X. Qiao, "Study on experiment of concrete compounding XYPEX and steel fiber," Applied Mechanics and Materials, vol. 105-107, pp. 1755-1759, 2012.

[23] S. Bohus, R. Drochytka, and L. Taranza, "Fly-ash usage in new cement-based material for concrete waterproofing," Advanced Materials Research, vol. 535-537, pp. 1902-1906, 2012.

[24] X. Zhang and D. Zheng, "Uniform design for preparation of cementitious capillary crystalline waterproofing coating," Advanced Materials Research, vol. 374-377, pp. 1491-1494, 2012.

[25] J. Pazderka, "Changes in water vapour permeability of concrete due to crystalline materials," Concrete, vol. 48 , no. 1, pp. 45-46, 2014.

[26] J. Pazderka, "Crystalline coating or crystalline admixture?" Concrete, vol. 48, no. 3, pp. 20-21, 2014.

[27] P. Reiterman and V. Bäumelt, "Long-term sorption properties of mortars modified by crystallizing admixture," Advanced Materials Research, vol. 1054, pp. 71-74, 2014.

[28] BSI, "Testing hardened concrete. Part 2-making and curing specimens for strength tests," BS EN 12390-2, BSI, London, UK, 2009. 


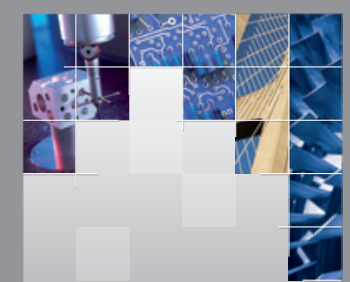

\section{Enfincering}
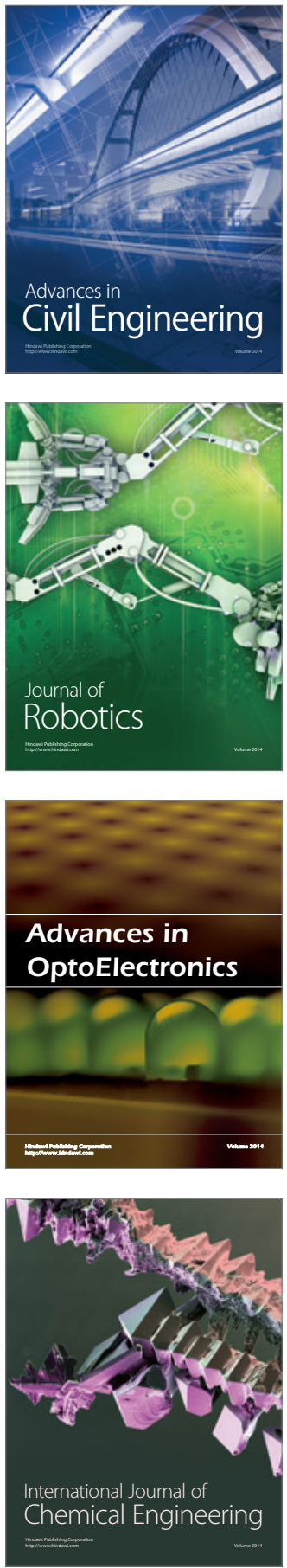

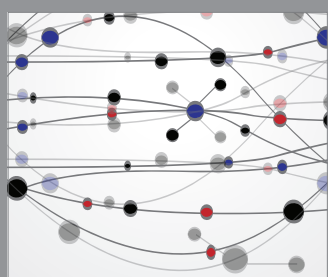

The Scientific World Journal

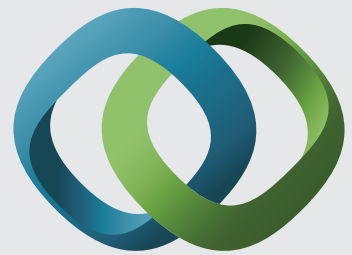

\section{Hindawi}

Submit your manuscripts at

http://www.hindawi.com
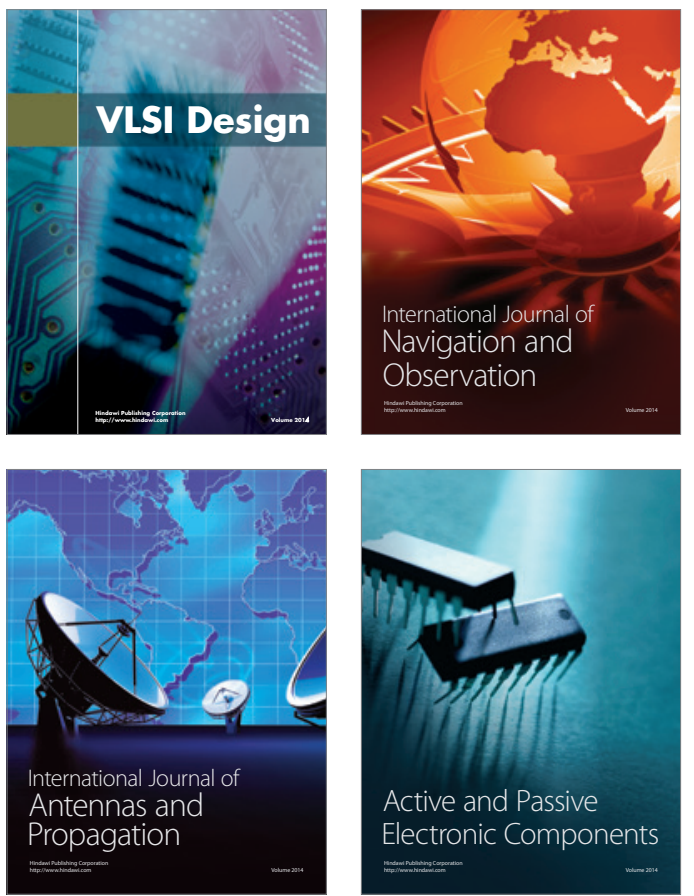
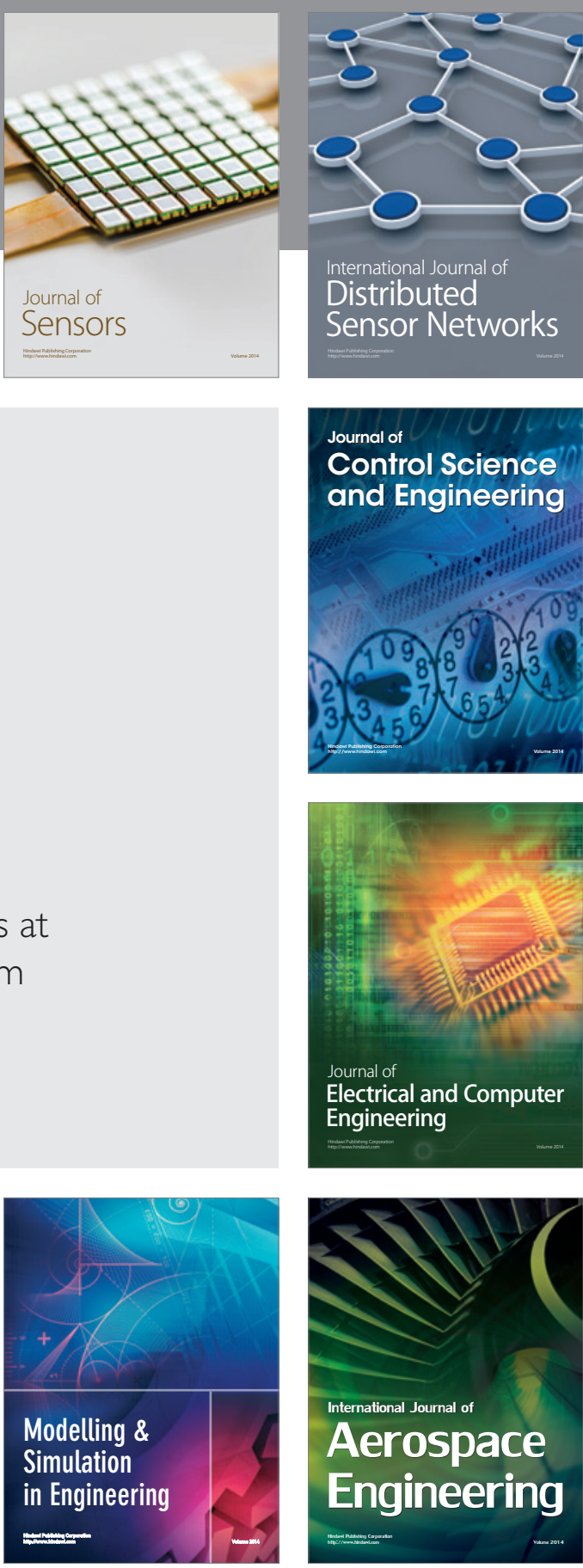

International Journal of

Distributed

Sensor Networks

Journal of

Control Science

and Engineering
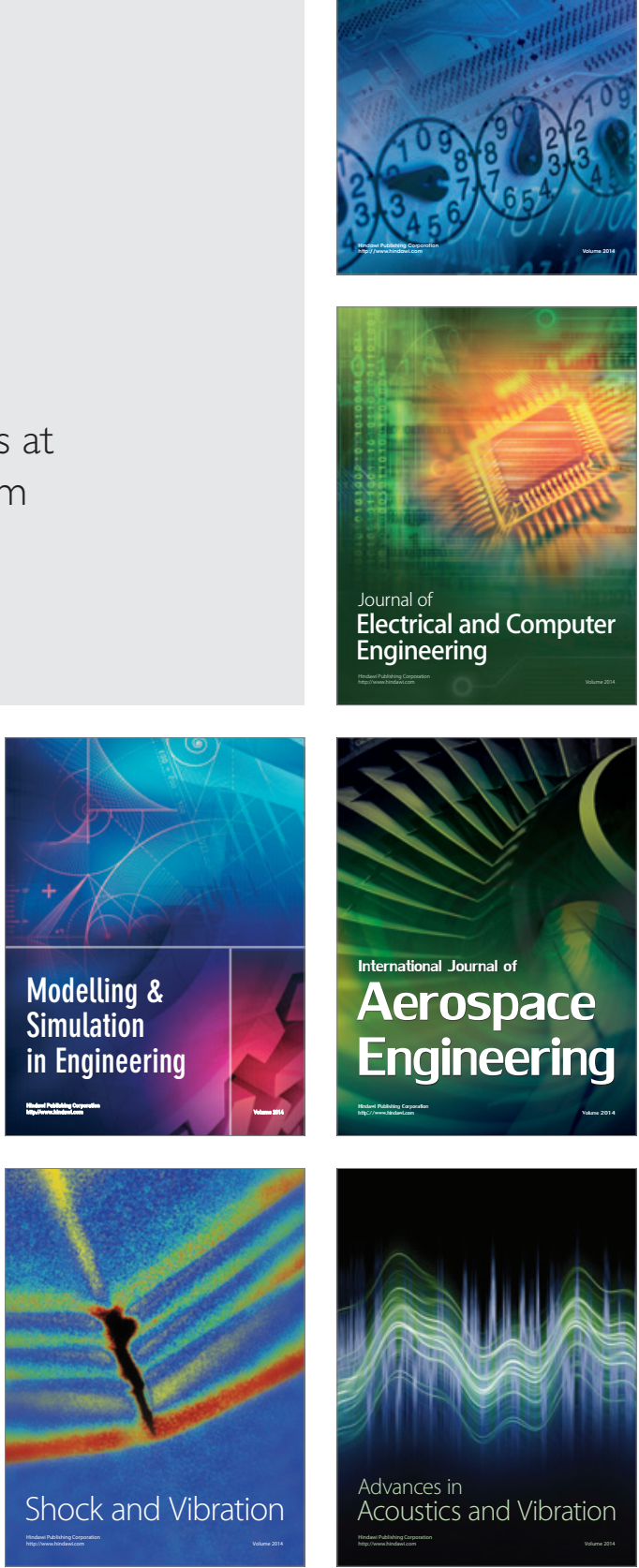